\title{
El posicionamiento de La Voz de Galicia durante la guerra civil española (1936-1939)
}

\section{The positioning of La Voz de Galicia during the Spanish Civil War (1936-} 1939)

\author{
Dra. Mercedes Román Portas \\ Universidad de Vigo | A Xunqueira s/n 36005 Pontevedra| España | http://orcid.org/0000- \\ 0002-2875-4053 | mroman@uvigo.es
}

\author{
Dra. Aurora García González \\ Universidad de Vigo | A Xunqueira s/n 36005 Pontevedra| España | http://orcid.org/0000- \\ 0003-3757-9047 | auroragg@uvigo.es
}

\author{
Dra. Lourdes Román Portas \\ Universidad de Vigo | A Xunqueira s/n 36005 Pontevedra| España | http://orcid.org/0000- \\ 0003-1366-9961 | romanportas@gmail.com
}

Fechas | Recepción: 05/04/2021 | Aceptación: 02/09/2021

\section{Resumen}

En los años anteriores a la guerra civil española, es decir en la II República, el diario coruñés La Voz de Galicia orientó sus contenidos siguiendo las indicaciones precisas que recibía de la dirección de prensa y propaganda y de los sucesivos organismos que le sucedieron. Las autoridades militares y civiles intervinieron durante aquellos años en el nombramiento de personas del consejo de administración, de directores del periódico y, de manera delegada a través de estos, del personal de la redacción. Sin embargo, la propiedad jurídica de la empresa permaneció siempre en poder de sus legítimos propietarios. La Voz de Galicia prefería poner en boca de otros sus preferencias y sus discrepancias con las iniciativas gubernamentales (Román, 1997). El objeto principal era mostrar que el periódico tomó sus medidas para incluir únicamente voces que resultaran afines al cometido común de ganar la guerra, buscando como todos apoyar al

\section{Abstract}

During the previous years to the Spanish civil war, in the II Spanish Republic, the Coruna's newspaper La Voz de Galicia guided its contents following the precise indications received from the press and propaganda Department and from the successive organizations that followed it. The military and civilian authorities participating during those years in the appointments of members of the administrative council and the newspaper director, these delegating in the edition team. However, the juridical property of the company always remained in the hands of its legitimate owners. La Voz de Galicia preferred that others expressed their preferences and disagreements in relation to the governmental initiatives (Román, 1997). The main object was to show that the newspaper took measures in order to include only opinions with some affinity with the common target of winning the war, trying as everyone else used doing. The article tackles with a descriptive and analytical methodology 
bando nacional. El artículo aborda con una metodología descriptiva y analítica el procedimiento de selección de los periodistas que cubrieron la información en aquel difícil período y muestra cómo el punto de vista de fuentes externas era considerado inevitablemente sesgado. De la misma manera, proporciona datos sobre el contexto en que se vivió el conflicto, tratando de mantener la fidelidad a los principios fundacionales del periódico.

Palabras clave: Guerra Civil, periodismo literario, La Voz de Galicia, ideología. the system for the selection of the journalists that covered the information in such difficult period and shows how the point of view of external sources was inevitably considered not reliable. In the same wide, it gives data related to the context that involved the conflict, trying to keep up a loyalty to the foundational principles of the newspaper.

Keywords: Civil War, Literary Journalism, La Voz de Galicia, Ideology.

\section{INTRODUCCIÓN Y METODOLOGÍA}

Este trabajo se centra en los momentos previos o antecedentes a la última guerra civil española. Muestra cómo ya con anterioridad La Voz de Galicia acudía a voces autorizadas para exponer el sentir del país, y estas voces servían al periódico para expresar sus propias convicciones. El recurso a autores de reconocido prestigio o el ejercicio del periodismo literario fue en el caso concreto de este diario regional, una de las formas de abordar asuntos que podían tener diferentes enfoques, e implicaciones morales, cuando estaban en juego los valores que se perseguían desde bandos enfrentados. La complejidad de los planteamientos brindaba la oportunidad de ofrecer además de hechos, comentarios y reflexiones que permitieran al lector formarse una opinión cualificada del conflicto bélico.

Con frecuencia se ha dicho que en la historia del periodismo, no son muchos los estudios monográficos centrados en el análisis de importantes diarios españoles. Afortunadamente esta laguna, en buena parte, ha empezado a llenarse con trabajos históricos rigurosos y profundos sobre periódicos como ABC (Iglesias, 1980), El Correo Español-El Pueblo Vasco (Sánchez, 1989), Diario de Navarra (Sánchez, 1983), El Debate, El Sol, Crisol y Luz (Redondo, 1970), etc. En lo que a historia de la prensa gallega se refiere, los estudios monográficos de diarios son aún escasos. Contamos con interesantes aportaciones históricas sobre Faro de Vigo (Altabella y Leal, 1965), El Correo Gallego (Blanco, 1978), La Región (Valladares, 1993), El Ideal Gallego (Fernández, 1993) y La Voz de Galicia (Fernández, 1993).

La guerra se sufrió en ambos bandos con gran intensidad y en ese difícil contexto el periódico intentó mantener una posición imparcial, combinar ideologías y presentar elementos para un balance unificador en aquel dramático momento. El texto muestra cómo influyó la guerra en la deriva del periódico, y cómo se realizó la selección de autores, con el fin de ayudar a esclarecer las circunstancias y contribuir a la formación de la conciencia colectiva en su ámbito regional.

La hipótesis de la que partió este trabajo fue que, en La Voz de Galicia, como en otros periódicos españoles ( $A B C$, Faro de Vigo, El Correo Gallego, La Región...), las comunicaciones y textos que se recibían desde el extranjero se trataron como puntos de vista externos e inevitablemente sesgados. 
El objeto principal era mostrar que el periódico tomó sus medidas para incluir únicamente voces que resultaran afines al cometido común de ganar la guerra, buscando como todos apoyar al bando nacional, y ello revirtió en un estricto procedimiento para nombrar personal tanto de dirección como de redacción, así como corresponsales y colaboradores. La empresa deseaba ser independiente, tal como establecían sus principios desde el primer editorial, pero era necesario mantenerla a flote.

La metodología seguida para alcanzar este objetivo partió de la revisión de los Libro de actas del Consejo de administración y memoria de accionistas, así como los ejemplares de La Voz de Galicia correspondientes a los años del conflicto y anteriores, y bibliografía específica sobre el tema; posteriormente se procedió al análisis descriptivo y de resultados hasta llegar a la exposición de los elementos que permiten establecer las conclusiones alcanzadas.

\section{CONTEXTO HISTÓRICO: PERIODISMO LITERARIO Y GUERRA CIVIL}

Poner en boca de escritores o personajes de reconocido prestigio las opiniones o ideas del país o del mismo periódico fue una práctica habitual en La Voz de Galicia (Román, 1997). Sirven como ilustración, en los años anteriores a la última guerra civil española, dos ejemplos publicados por el periódico. La Voz prefería poner en boca de otros su visión de los hechos. Así, en abril de 1931, una carta de Pedro Salinas a Jorge Guillén:

Estamos hoy en España en un estado espiritual de guerra civil y creo que pronto se llegará al estado real; creo que la monarquía va hacia su fin al galope. Ya verás su insensata conducta cada día más probatoria de ceguedad suicida. Este gobierno está ya gastado y desacreditado; el conflicto escolar se presenta como muy grave; la crisis de autoridad es absoluta; preveo para antes de tres meses la República traída como desde el primer momento por la contumacia del monarquismo, pero entonces es cuando la situación se hará más grave. Esa República no tiene viabilidad ni por sus amigos ni por sus enemigos; días de lucha menuda y continua de zancadilleo de restauración amenazante, de inestabilidad en todos los sentidos, de aspereza y amargura en el ambiente. (La Voz de Galicia, 2 de abril de 1931)

Un año más tarde, unas palabras de Unamuno publicadas también en El Sol con una crítica a la retirada de los crucifijos de las escuelas:

En estos días las mujeres, las madres de una famosa villa de esta provincia de Salamanca, se amotinaron al saber que se iba a quitar el crucifijo de las escuelas y ha habido que dar satisfacción al sentimiento de ese movimiento popular contra una orden disparatada. Disparatada, y perdónenos el que la haya dado, de inspiración no sólo antinacional, antipopular, y antihistórica, sino también antipedagógico. La presencia del crucifijo en las escuelas no ofende a ningún sentimiento, ni aún al de los racionalistas y ateos, y el quitarlo ofende el sentimiento popular hasta de los que carecen de creencias confesionales. ¿Que se va a poner donde estaba el tradicional Cristo agonizante? ¿una hoz y un martillo? ¿un compás y una escuadra? ¿o que otro emblema confesional? porque hay que decirlo claro $y$ en ello tendremos que ocuparnos: la campaña contra el crucifijo en las escuelas nacionales es una campaña de origen confesional claro que de confesión anticatólica y anticristiano. Porque lo de la neutralidad es una engañifa. (La Voz de Galicia, 31 de enero de 1932, p. 4) 
Todo un posicionamiento en momentos difíciles en la historia de España, que utilizaría con más cautela cuando los acontecimientos sorprendieron al periódico. La situación política en España en 1936 era tan desastrosa, que lo que ocurrió podía haber sucedido en cualquier país en las mismas circunstancias; el país sólo tenía dos alternativas: someterse al atropello u optar por la violencia (Payne, 2017).

\section{ANÁLISIS DESCRIPTIVO Y DE RESULTADOS. EL RUMBO DEL PERIÓDICO DURANTE LA GUERRA}

El 19 de julio de 1936 La Voz de Galicia informaba de un intento subversivo contra la República; el periódico no se publicó los cuatro días siguientes; hasta que los sublevados triunfaron en la Coruña. Los primeros días fueron de gran confusión. Ni el gobierno ni los autores del movimiento podían asegurar si había tenido éxito o no. "La guerra era un secreto a voces y el Gobierno no sólo la aceptó, sino que la buscó. Según sus cálculos, el Ejército republicano aplastaría el levantamiento, y la República saldría reforzada" (Payne, 2017).

El 24 de julio unos titulares en La Voz de Galicia, fueron causa de multa al director: "Un trágico episodio nacional. Breves apuntes de los trascendentes acontecimientos de cuatro días. Cómo se desarrollaron los graves sucesos en la Coruña". Aparecían en portada cuatro fotografías; una de un cañonazo en la fachada del teatro Rosalía; barricadas en la calle Real y bajo los soportales del gobierno civil, y dos barcos llamados "hidros" en la dársena. Desde aquel día el diario abriría con un recuadro en primera página:

La autoridad militar ha declarado de servicio público la edición de los diarios locales y ordenado que desde la mañana de hoy sean publicados a fin de contribuir al patriótico propósito de tranquilizar los espíritus y afirmar plenamente la normalidad. Orden de la autoridad militar: al objeto de reanudar la publicación de la prensa diaria en esta ciudad se comunica al personal perteneciente a las empresas de la misma que deberá presentarse desde el momento de la publicación de esta nota a las horas en que normalmente acostumbrase a hacerlo haciendo saber a dicho personal que dado el carácter público de estas empresas en el momento actual, a partir de las 12 horas del día de mañana será militarizado, caso de no haber efectuado su presentación. En virtud de esta disposición nuestros empleados, cumpliendo el deber que se les imponía, han concurrido al trabajo para la confección de este número. (La Voz de Galicia, 24 de julio de 1936)

El personal fue en efecto, militarizado, según Libro de Actas, (1936, 19 de agosto). La autoridad militar estableció servicios para la guardia del edificio, de los talleres y para acompañar al personal al ir y volver del trabajo. El periódico dependía entonces del negociado militar de prensa, radio y propaganda "que interesó de esta empresa antecedentes y datos diversos y que constantemente envía para su inserción preferente, patrióticos artículos, trabajos, entre filetes, etc. con que se honran nuestras columnas".

Los medios de información de uno y otro bando se pusieron al servicio de un fin, ganar la guerra. Algunos complacidos, otros obligados y los que no coincidían con el bando en el que les había tocado, fueron incautados. La Voz de Galicia mantuvo durante toda la contienda la propiedad física del periódico. El contenido del diario en aquellos casi tres años fue similar al de otros diarios de la zona franquista. En ambos bandos, la información y comentarios de los periódicos iba encaminada no sólo a elevar la moral de los combatientes, sino a convencer a 
las respectivas retaguardias de la victoria final. Se exaltaban los triunfos propios, se minimizaban o suprimían los del bando contrario y se contrarrestaban los argumentos que el enemigo difundía a través de emisoras de radio.

La Voz de Galicia publicaba cada día un resumen de las charlas de Queipo de Llano desde Radio Sevilla. El 25 de julio ante la próxima caída de Madrid empezaba diciendo:

La situación se presenta cada vez más clara (...) También explicaba por qué aquel día no se publicaba el tradicional extraordinario del día del apóstol: "Número extraordinario aplazado. Para ser publicado hoy, día de Santiago y de Galicia, preparábamos un número extraordinario, con valiosas colaboraciones de distinguidas personalidades y de ilustres artistas escritores y periodistas gallegos. Las circunstancias de los pasados días y las condiciones en que se realiza la distribución del periódico nos han obligado a aplazar hasta la fecha más propicia la edición del citado extraordinario, consagrado a la solemne fiesta, a Galicia y a España cuyo patrón es el glorioso Apóstol. (La Voz de Galicia, 1936, 25 de julio de 1936, p. 1)

La Junta de Defensa Nacional dictó un bando para controlar los medios de comunicación y ponerlos al servicio de la causa de los sublevados. Declaró sometidos a la jurisdicción de guerra por procedimiento sumarísimo los delitos realizados por medio de la imprenta u otro medio cualquiera de publicidad, y se consideraría rebeldes a los que propalasen noticias falsas o tendenciosas. Se sometían a la previa censura dos ejemplares de todo impreso o documento destinado a la publicidad y se prohibía el funcionamiento de todas las estaciones de radio y emisoras particulares. Se acordó la creación de un gabinete de prensa para organizar aquel servicio.

También se pedía que quien tuviese noticias comprobadas de desmanes y violencias cometidas por los rojos, remitiesen al gabinete informes detallados y firmados, haciendo constar el domicilio del remitente. El gabinete, pasó a denominarse Oficina de Prensa y Propaganda.

El diario distribuyó un elevado número de ejemplares gratuitamente en los frentes de operaciones, hospitales y dependencias militares e insertó gratuitamente esquelas y anuncios de servicios destinados a fines patrióticos y panfletos que se lanzarían desde los aviones sobre todo en zona roja.

Un decreto de la Junta de Defensa Nacional, obligó a reducir la superficie de los periódicos, por lo que La Voz de Galicia pidió a colaboradores y corresponsales que limitasen sus trabajos e informaciones a lo indispensable La Voz de Galicia, (17 de septiembre de 1936, p. 1)

\subsection{El enfoque de los contenidos}

También los contenidos mostraron el posicionamiento del periódico sometido a las directrices que se le imponían. Desde sus páginas se defendió con gran empeño la unidad de España. Cualquier tipo de nacionalismo, separatismo o regionalismo era algo que había que aniquilar. Artículos como éste explicaban cómo se entendía la unidad de España:

Cuando hablamos de la España una, cuando luchamos contra el separatismo, no nos mueven bajos rencores regionales ni tratamos de mantener oposición cerril a sentimientos hondamente arraigados en el alma regional. Tampoco tratamos de hallar 
una solución mediocre y contemporizadora, haciendo distingos bobos entre unidad nacional y unidad administrativa. La Voz de Galicia, (18 de septiembre de 1936, p. 1)

Diariamente se publicaban frases dirigidas a sectores determinados de la sociedad: capitalistas, mujeres coruñesas, patronos, comerciantes, obreros. A los capitalistas se les pedía que parte de lo que poseían lo entregaran al tesoro nacional del gobierno de Burgos, por ejemplo; a las mujeres de la Coruña que confeccionasen chalecos de punto con destino a los soldados del frente. (La Voz de Galicia, 18 de octubre de 1936, p. 2)

El 29 de septiembre Franco fue proclamado jefe de gobierno del nuevo Estado español. Asumía con todos los poderes el mando supremo de los ejércitos y operaciones. El tres de octubre La Voz de Galicia reprodujo el texto de la ley de organización y estructuración del nuevo estado, firmada en Burgos. El editorial del diario exhortaba a los coruñeses acudir a la plaza de María Pita, donde iba a darse la noticia oficial del nombramiento de Franco. El consejo de administración envió un telegrama de felicitación y adhesión. Se insertaban frases de Franco, José Antonio, Hitler y consignas como:

Consignas: contra los caciques emboscados. Contra los que pretenden actuar de cuña que distienda y desvirtúe la profunda, profundísima, transformación social y política que se impone. Contra los lobos con piel de cordero. Contra los rojos y sus simpatizantes, también emboscados. Contra los potentados avarientos... (La Voz de Galicia, 6 de noviembre de 1936, p. 3)

Y diariamente el lema: “una patria, un estado, un caudillo. Una patria: España. Un caudillo: Franco".

Una orden del 23 de diciembre prohibió libros, periódicos, folletos y toda clase de impresos pornográficos o de literatura socialista, comunista, libertaria y en general disolvente, obligando a sus propietarios a entregar los establecimientos a las autoridades. La Voz de Galicia, (4 de diciembre de 1936, p. 1)

A finales de año, se reprodujeron las disposiciones de la Dirección de Prensa y Propaganda transmitidas por Radio Salamanca:

10 Serán publicados en la prensa, a partir de esta fecha, los partes oficiales del cuartel general del generalísimo y ejército ocupando el lugar del artículo de fondo (primera plana) y a continuación se insertarán todas las publicaciones, informes, artículos, órdenes y avisos que remitan dicha dirección y las autoridades locales militares y civiles, y las noticias y disposiciones que se transmitan por Radio Salamanca. Aquellos periódicos que por circunstancias determinadas reciban esas informaciones con retraso, las insertarán en el número siguiente, pero en el lugar preferente citado.

2‥ En lo sucesivo se enviarán a la dirección de prensa y propaganda dos ejemplares de cada periódico y de toda clase de publicaciones, haciendo la remisión por los medios más rápidos de transporte.

3‥ En todas las emisiones en que se den comunicados y noticias oficiales, se hará sonar previamente el himno de la legión, "Valiente y leal legionario", terminando con el de Falange o Requetés. (La Voz de Galicia, 3 de diciembre de 1936)

Entre otras cosas se aconsejaba escuchar la voz del mando y del patriotismo expresada por nuestros medios de transmisión que son la radio y la prensa y concretaba, además: “todo buen 
español habrá de leer, por lo menos, un periódico diario, o cuantos pueda de los publicados por la España liberada. No deben oírse de ninguna manera las propagandas hechas por la radio de nuestros enemigos..." La Voz de Galicia (5 de enero de 1937).

El día 19 de enero se inauguró Radio Nacional de España en Salamanca, con un discurso de Franco a los españoles. El último día de enero La Voz de Galicia insertaba la siguiente nota del delegado de prensa y propaganda:

El silencio patriótico es el que guarda el público cuando la radio nacional previene que se van a dar importantes noticias e informaciones de la guerra. Debe observarse silencio al oírse repetida la advertencia, por tres veces consecutivas: atención, atención, atención. Así lo espera el caudillo. Viva España. Viva Franco. (La Voz de Galicia, 31 de enero de 1937)

Un artículo del 28 de febrero se refería a la radio, como instrumento decisivo para ganar la guerra. La Delegación de Prensa y Propaganda encargó a La Voz de Galicia, en exclusiva, la corresponsalía de venta y propaganda del semanario La Ametralladora. En abril el coruñés Manuel Arias Paz fue nombrado delegado Nacional del Estado para Prensa y Propaganda La Voz de Galicia, (1937, 15 de abril, p. 1). Poco después solicitó datos de la empresa La Voz de Galicia: capital, accionistas, personal de redacción y administración, datos de tirada, de consumo de papel, maquinaria, teletipos, etc.

\section{LOS NOMBRAMIENTOS DE PERSONAL}

El procedimiento de selección de los periodistas resulta una aportación interesante sobre el contexto, mientras se intentaba mantener la fidelidad a los principios fundacionales del La Voz de Galicia y muestra cómo el punto de vista externo era considerado inevitablemente sesgado.

El 13 de agosto de 1937 la empresa de La Voz convocó junta extraordinaria de accionistas para aprobar cambios del Consejo de Administración. El 28 de julio se había acordado la siguiente organización:

Presidente: Emilio Rey Romero.

Vicepresidente: Ricardo Fernández Cuevas.

Secretario: Luis Molina.

Vocales: Alfonso Molina Brandao, Enrique de la Torre, Joaquín Ozores y Manuel Casariego.

Cuando se reunió el Consejo en sesión extraordinaria, Emilio Rey comunicó que: "él y Alejandro Barreiro Noya (director del periódico desde 1914) habían sido convocados por el gobernador civil a una reunión en la que se encontraba Maximiano García Venero y otros jefes de FET y de las JONS: en ella y a presencia de aquella autoridad, tomó posesión el señor García Venero de la dirección de La Voz de Galicia cuyos poderes le transmitió el señor Barreiro; y el señor Gobernador hizo entrega a nuestro presidente de las instrucciones dictadas por la delegación del Estado para Prensa y Propaganda para este caso" (Libro de actas, 17 de agosto de 1937).

La empresa tenía que proponer a la Delegación de Prensa y Propaganda una terna de personas para que eligiese al consejero delegado que no podía ser funcionario en activo del Estado, provincia o municipio. Ante la imposibilidad de poder presentar la terna, por las profesiones y 
destinos de los consejeros, se acordó proponer a Emilio Rey Romero para el cargo de consejero delegado (Libro de actas, 20 de agosto de 1937).

Barreiro cesó en su cargo y fue sustituido por García Venero. El nuevo director entró en la reunión del Consejo de Administración, para conocer a sus miembros e indicó brevemente sus propósitos. Nombró redactor jefe a Martínez Pereiro, y desde el día 17 se cambió la mancheta, se dejaron de insertar los precios de suscripción y la frase en que decía ser el diario de mayor tirada en Galicia; e incluyó párrafos como el siguiente:

En la España nacional ha desaparecido la lucha de clases. Todos los españoles nos integramos en la comunidad hispánica, a la que el caudillo da patria, pan y justicia. Por esto tornamos a ser una unidad de destino en lo universal. (La Voz de Galicia, 17 de agosto de 1937)

A finales de agosto García Venero viajó a Santander desde donde enviaría al periódico información sobre los acontecimientos militares en aquella zona. Sus artículos comenzaron a publicarse desde el 5 de septiembre: "mañana La Voz de Galicia comenzará a publicar 'Origen, intimidad y horror de las jornadas rojas en Santander' por Tresgallo de Souza". (La Voz de Galicia, 5 de septiembre de 1937, p. 1)

A partir de octubre los acontecimientos se precipitaron. El nuevo director despidió a la casi totalidad de la redacción, incluido el recién nombrado redactor jefe, Martínez Pereiro, que fue sustituido por Jesús Vasallo Ramos. Como consecuencia, Antonio Carballo Tenorio, presentó su dimisión. Y en noviembre expulsó a Alejandro Barreiro de la redacción "sin que de ello diera explicaciones ni conocimiento al delegado de la empresa". (Libro de Actas del Consejo de Administración, noviembre de 1937)

En medio de la inquietud y agitación del personal, el 19 de octubre, Emilio Rey escribió al Subdelegado de Prensa y Propaganda:

Señor don José Moreno Torres. Conde de Santa Marta de Vadillo. Subdelegado Nacional de prensa y propaganda. Salamanca. Querido amigo: después de las conversaciones sostenidas por las que estás debidamente informado, el Consejo de gobierno y administración de esta empresa en reunión particular celebrada ayer, ha acordado comunicarte que la terna de directores es imposible presentarla en estos momentos por no contar con persona de absoluta confianza y al mismo tiempo de garantizada capacidad para dicho cargo cosa que más adelante será fácil de solucionar y en vista de ello te propone el que yo sea director. De esta forma asumiría toda la responsabilidad, haría la limpieza necesaria en este diario y podría compaginar la parte administrativa con la directiva y en nada cambiaría esto, respecto a la idea que esa delegación de prensa y propaganda tenía, garantizada en este caso por mí. Nada quiero decirte de mi manera de pensar respecto al glorioso movimiento pues tú estás perfectamente enterado de mi actuación desde el primer momento y de la de todos los compañeros del actual consejo. Espero que tomes cuenta del interés de este asunto dada la importancia que tiene para la propaganda única del Estado y para la empresa pues como estás enterado de todo te das perfecta cuenta. Esperando tus gratas noticias con el interés que puede suponer recibe un abrazo de tu amigo. Emilio (Archivo de La Voz de Galicia) 
No se aceptó a Emilio Rey como director, a pesar de su intento, sino que se nombró a Francisco Bravo, y el 25 de noviembre se comunicó a los miembros del Consejo de Administración que la Delegación de Prensa y Propaganda y el secretario general de FET y de las JONS habían destituido a García Venero como director de La Voz de Galicia y se le había expulsado del citado organismo nacional.

Francisco Bravo tomó posesión el 18 de diciembre. El último día del año Emilio Rey comunicó al consejo de administración que había despedido a los redactores: Augusto Barreiro Noya, José Blanco Meizoso y Jesús Merelas Bello, por considerarlos desafectos a la empresa. Y a la mecanógrafa María Ramos, admitida por García Venero, por carecer de utilidad su labor.

El 1 de enero de 1938 La Voz insertó una fotografía con este pie: "tiempos heroicos. 16 de junio de 1935 en Gredos. Los nacional sindicalistas deciden ir a la insurrección" (La Voz de Galicia, 1 de enero de 1938, p. 1). En la foto aparecían José Antonio Ruiz de Alda, Onésimo Redondo y Francisco Bravo. Éste tampoco permanecería mucho tiempo al frente de La Voz de Galicia. El 22 de abril reprodujo de Diario de Burgos el discurso del General Yagüe en el aniversario del decreto de unificación. La tirada se volvió a publicar el día 23 La Voz de Galicia, (1938, 23 de abril). El discurso no agradó a las autoridades, Diario de Burgos fue suspendido, La Voz de Galicia multada y Francisco Bravo cesado.

El 31 de enero de 1938 se constituyó un nuevo gobierno en Burgos. La prensa fue regulada por una Ley, en realidad, un decreto promulgado en plena guerra civil el 22 de abril de 1938, que llegaría a tener una vigencia de 28 años. En febrero de aquel año, un editorial de La Voz de Galicia preparaba así el terreno:

Indudablemente, si el Estado va a revestir las características de totalitario, tendrá que afrontar este asunto (...) La prensa tiene que estar al servicio del estado, atender sus consignas, seguirle en sus iniciativas y colaborar con él en la formación política y cultural de las masas. No es posible la subsistencia del régimen de la prensa, tal como existía en los tiempos demo liberales. (La Voz de Galicia, 12 de febrero de 1938, p. 1)

Sobre todo, en los primeros tiempos, los preceptos de esta ley fueron aplicados con innegable rigor (García González, 2009). Este ordenamiento preveía el castigo gubernativo de "todo escrito que, directa o indirectamente, tienda a mermar el prestigio de la Nación o del Régimen, entorpezca la labor del gobierno en el nuevo Estado, o siembre ideas perniciosas entre los intelectualmente débiles" (arto 18).

En editorial de La Voz de Galicia del 3 y 4 de mayo, recién promulgada la ley de prensa decía entre otras cosas:

No más libertinajes estúpidos, que demasiado sabemos a lo que conducen. Libertad, en un acorde perfecto de voluntad de servicio y de orientación para el pueblo, en suma, esencia de nuestra doctrina. De ahí nacerá la derrota de nuestros enemigos. Y se ganará la guerra. (La Voz de Galicia, 3 de mayo de 1938)

La prensa regional, sujeta a las directrices que se marcaban, se entregaría desde entonces a una labor de propaganda de los principios políticos del franquismo y quedaría reglamentada estrechamente por medio de la imposición de las llamadas "consignas de prensa". Desde que Francisco Bravo asumió la dirección de La Voz de Galicia en la cabecera del diario se insertó la efigie de Franco y el yugo y las flechas. 


\subsection{La selección de personal, corresponsales y agencias}

Un decreto del Ministerio del Interior, que desarrollaba la ley del 22 de abril de 1938, fijó la plantilla mínima de los periódicos desde el 1 de octubre y su retribución. La plantilla de todos los diarios excepto los de Madrid y Barcelona constaría obligatoriamente de: director, redactor jefe, y varios redactores: político (ayuntamiento, gobierno civil, diputación, movimiento), de política extranjera, mesa, sucesos, deportes y espectáculos, un taquígrafo y un fotógrafo. El decreto señalaba la retribución de cada uno y prohibía rebajar sueldos que estuviesen en vigor, o realizar despidos sin perjuicio del derecho a amortizar vacantes en cuanto fuese compatible con la plantilla que determinaba. En este momento se ofreció a Alejandro Barreiro volver a ser redactor del diario "toda vez que fue necesario suprimir las colaboraciones como la que tenía el señor Barreiro en vista de la orden del ministerio del interior fijando la nueva plantilla y los sueldos que ha de tener el personal de redacción" (Archivo de La Voz de Galicia), pero Barreiro no aceptó y cesó definitivamente de prestar sus servicios a La Voz de Galicia.

Manuel Sánchez Marín que estaba al frente de la administración desde 1934 con el título de cajero, en agosto de 1938 fue nombrado administrador, con las funciones y atribuciones que venía desempeñando (Libro de actas 16 de agosto de 1938). Muchas de las personas que trabajaban en oficinas y talleres fueron llamadas a filas, con el consiguiente perjuicio para el periódico. Se aprobó la admisión temporal de personal auxiliar y de familiares de las personas ausentes. En relación con los obreros hubo cambios de carácter empresarial. Hasta entonces, según las bases de trabajo que regían, la empresa abonaba directamente los jornales a los obreros enfermos. A partir de enero de 1937, tuvo que incluir al personal obrero en el subsidio de enfermedad, y pagar una cuota mensual al estado.

Tras el decreto de 1 de octubre de 1938, con la reorganización de las plantillas de los periódicos, la redacción de La Voz de Galicia quedó constituida así (entre paréntesis se señala el sueldo mensual que correspondía a cada uno):

Director: Antonio Álvarez Solís (1000).

Redactor jefe: Jesús Vasallo Ramos (800).

Sucesos: Manuel Díaz Martínez (400).

Político: Manuel Pillado (400).

Mesa: Francisco Alfonso Merchán (400).

Política extranjera: José Francisco Pérez (400).

Deportes y espectáculos: Manuel Ponce Patiño “Plongeón” (400).

Taquígrafo: Pedro de Llano (400).

Buena parte de la información de estos años estuvo a cargo de corresponsales o de agencias de noticias. La Voz de Galicia publicó, por ejemplo, las crónicas que desde el frente envió Enrique Mariñas. Mariñas fue el primer locutor de radio Coruña hasta que movilizado en 1937 se convirtió en corresponsal de guerra para los servicios militares. También publicó las crónicas que desde el frente de Teruel enviaba Luis Torres.

A través de El Correo Español, La Voz de Galicia recibió información del congreso nacionalsocialista de Nuremberg, que tuvo lugar en septiembre de 1938:

El Correo Español de Bilbao, ha destacado a Nuremberg un redactor que le enviará crónicas especiales del congreso Nacional socialista. El Correo Español ha tenido la 
gentileza de hacernos partícipes de este servicio y La Voz de Galicia y él serán por lo tanto los únicos que las publicarán en España. La Voz de Galicia (1938, 8 de septiembre).

El día tres de ese mes nació la sección hace 50 años, que recogió noticias del 2 de septiembre de 1888. Y el día seis empezó a publicar bajo el título "Estampas" las crónicas de Álvaro de Hispania (relatos de un evadido), con sus impresiones vividas en la zona roja:

Álvaro de Hispania, oculta el nombre de una ilustre personalidad que en una etapa de honestidad y patriotismo, ocupó puestos de responsabilidad en la gobernación del estado. Estamos seguros de que serán muy leídas estas impresiones de Álvaro de España. (La Voz de Galicia, 6 de septiembre de 1938)

Corresponsales que enviaban con frecuencia artículos fueron: L. Puente "Spectator" desde Asturias. Fernando Lara, que escribió una serie de artículos "Horizontes azules" sobre acciones de la Armada nacional. En febrero de 1937 el consejo de administración aprobó la colaboración de crónicas de guerra de Víctor Ruiz Albéniz "El Tebib Arrumi", cronista oficial del cuartel general, a razón de 50 pesetas por cada una publicada. Envió sus crónicas durante toda la guerra. En agosto más o menos al tiempo que entraba nuevas personas en el consejo de administración y cambiaba el director, "se sustituyeron también algunos corresponsales de marcada significación extremista o desafectos a la gloriosa causa nacional" (Libro de actas 12 de agosto de 1937).

Hasta diciembre de 1936 había contado con la colaboración de Luis Moure Mariño, Dámaso Calvo, el doctor Devesa y Joaquín Purón. En diciembre de 1936 se cancelaron las colaboraciones de años anteriores y "también se dejó de trabajar con algunos activos corresponsables y por ejemplo para Monforte se nombró al abogado Sánchez Tain" (Libro de actas 28 de diciembre de 1936).

La Voz de Galicia aceptó como colaboradores a Conde de Riera y Jiménez de Llano. También llegaban al periódico colaboraciones de otras personas que por falta de espacio o por otros motivos no siempre pudo publicar.

En el segundo aniversario del inicio de la guerra publicó un extraordinario de 12 páginas con artículos de Juan Ignacio Luca de Tena: "Origen y razón de ser del movimiento nacional español"; Rogelio Róspide: "Episodios inéditos de Madrid". Joaquín Romero: "Madrid". Alejandro Barreiro Noia (Santiago del Burgo): "Galicia en la guerra". Jesús Vasallo: "Romance del lobo pardo". Francisco V. Montalbán: "Un servicio de nuestra aviación". Enrique Mariñas: "En los riscos de Alcubierre". Etc.

Por un contrato con la agencia Logos de San Sebastián, desde mediados de enero 1937 publicó artículos de colaboradores nacionales: Eugenio D’Ors, Luis de Idiaquez, José María Salaverría, Luis Rosales, Torrente Ballester, Álvaro Cunqueiro, Francisco Bravo, etc.

Además de Logos, La Voz de Galicia trabajó durante la guerra civil con otras agencias de noticias. Desde febrero de 1938 con Faro, de Burgos:

Se da cuenta al consejo del nuevo servicio telegráfico que establece la empresa con la importante agencia telegráfica Faro, de Burgos. Se hace constar el haber llegado a un acuerdo con la misma a fin de que suministre todos los datos, noticias nacionales, 
extranjeras y crónicas de guerra por 400 Pts mensuales". (Libro de actas 24 de febrero de 1938)

Contrató con Faro dos conferencias telegráficas de 15 minutos diarios y otra gratuitamente con la agencia Stefani, también de Burgos. De vez cuando publicó algunas noticias de la agencia Dux. Desde el 11 de octubre de 1938 recibió información extranjera de la agencia alemana D.N.B. (Deustches Nachirchtenbürg):

Desde hoy La Voz de Galicia de Galicia empezará a publicar una selecta información del extranjero que nos facilitará a nosotros, exclusivamente para La Coruña, la agencia DNB, una de las de mayor prestigio en Europa. Se trata de una información de última hora que vendrá a completar la copiosísima que ya venimos recibiendo por radio y de nuestras agencias Faro y Stefani. Esperemos que así nuestros lectores encuentren en La Voz de Galicia una información completísima. (La Voz de Galicia, 11 de octubre de 1938)

A partir de enero de 1939 la recién creada agencia Cifra sirvió información gráfica a La Voz. Emilio Rey acudió, en Burgos, a principios de 1939 a una reunión con el ministro de gobernación Serrano Suñer para la constitución de una agencia telegráfica nacional que se denominó Efe, a la que La Voz de Galicia contribuyó con 10.000 Pts.

\section{CONCLUSIONES}

Las conclusiones que aquí se enumeran, son una síntesis muy ajustada de la parte sometida a medición y algunas inferencias derivadas de la misma. Se corresponden únicamente con el trabajo de análisis y clasificación realizado sobre el material disponible del que cabe extraer lo siguiente:

-La Guerra Civil aparece en las páginas de La Voz de Galicia como un capítulo negativo de la historia de España, y se trata como tal en todo momento.

-A pesar de no abordarse directamente el conflicto bélico, es posible asegurar que no fue imparcial ni en el tratamiento de los distintos bandos, ni en el número de noticias que se dedicaron a cada uno de ellos.

-En sus páginas se muestra cómo Franco partió de la gran influencia de la prensa, y la usó primero como arma de guerra y después como instrumento de poder.

- La Voz de Galicia orientó sus contenidos siguiendo indicaciones precisas de la dirección de prensa y propaganda y de los sucesivos organismos que le sucedieron.

-Las autoridades militares y civiles intervinieron en el nombramiento de personas del consejo de administración; nombraron directores del periódico y a través de estos al personal de redacción.

-La propiedad jurídica de la empresa estuvo siempre, sin embargo, en poder de sus legítimos propietarios.

En cualquier caso, la historia de la Guerra Civil, contada por la Voz de Galicia, no puede separarse del contexto social y político en que se produjo. Por tanto, resultará también interesante analizar el resto de los materiales que conserva para completar la visión histórica que aportan. 


\section{Referencias}

Altabella, J. y Leal, F. (1965). Faro de Vigo y su proyección histórica. Editora Nacional.

Blanco, L. El Correo Gallego: Cien años de aportación a la historia 1878-1978. Ed. Compostela

Colección de La Voz de Galicia 1930-1939. Ejemplares consultados en papel en el archivo de La Voz de Galicia. https://www.lavozdegalicia.es/hemeroteca/

Fernández, C. (1993). EL Ideal Gallego 75 años de historia (1917-1992). Ediciós do Castro.

Fernández, C. (1993). La Voz de Galicia. Crónica de un periódico (1882-1992). Ediciós do Castro.

García González, A. (2009). Historia de la empresa "La Voz de Galicia" (1939-1992). LibrosenRed

García González, A. (2002). "La voz de Galicia y el régimen de censura y de consignas” en García Galindo, J.A.; Gutiérrez Lozan, F. y Sánchez Alarcón I. La comunicación social durante el franquismo. CEDMA.

Iglesias, F. (1980): Historia de una empresa periodística. Prensa Española. Editora de ABC y Blanco y Negro (1891-1978). Ed. Prensa Española.

Libro de Actas del Consejo de Administración de La Voz de Galicia S.A. Fuentes archivísticas.- Consejo de Gobierno y administración. 1930-1939. Documentos conservados en el archivo de la empresa. Puestos a disposición de las autoras. Inéditos.

Memorias de accionistas de La Voz de Galicia. Fuentes archivísticas. 1930-1939. Documentos conservados en el archivo de la empresa. Puestos a disposición de las autoras. Inéditos.

Documentos conservados en el archivo de la empresa. Puestos a disposición de las autoras. Sin publicar.

Payne, Stanley G. (2017). En defensa de España: desmontando mitos y leyendas negras. Espasa

Redondo, G. (1970). Las empresas políticas de José Ortega y Gasset. El Sol, Crisol y Luz (1917-1934). Rialp.

Román Portas, M. (1997). Historia de La voz de Galicia. Servicio de Publicaciones Universidad de Vigo.

Sánchez, A. (1989). El Correo Español-El Pueblo Vasco y su entorno informativo (1910-1985). Ed. Servicio de Publicaciones de la Universidad de Navarra.

Sánchez, J.J. (1983). Navarra en 1900: los comienzos del Diario. Ediciones y Libros.

Sinova, J. (1989). La censura de prensa durante el franquismo. Espasa Calpe.

Valladares, E. (1993). Historia de una empresa periodística gallega: La Región. Ed. Universidad Complutense de Madrid.

\section{Semblanza de las autoras}

Mercedes Román Portas es Profesora Titular del área de Periodismo de la Universidad de Vigo (Campus de Pontevedra). Doctora en Ciencias de la Información por la Universidad de Navarra y Licenciada en Historia por la Universidad de Valladolid. En la actualidad imparte docencia en el grado en Comunicación Audiovisual, en la materia Teoría e Historia de la Comunicación. Las líneas de investigación están centradas en la Historia de la Comunicación. Ha puesto en marcha y ha dirigido el máster y el doctorado en Investigación en Comunicación en la Universidad de Vigo. Ha dirigido 20 tesis doctorales.

Aurora García González es Catedrática de Periodismo en la Universidad de Vigo. Doctora en Comunicación Pública y, profesora de Opinión Pública en la Facultad de Ciencias Sociales y de la Comunicación de la Universidad de Vigo. Ha publicado diversos trabajos de investigación en 
el campo de la comunicación, entre otros: "La percepción de padres e hijos sobre las redes" en Comunicar (2021), "Reportaje sonoro y podcasting, el despertar de un género durmiente en España. El caso de Podium Podcast" en Estudios del Mensaje Periodístico (2020), o "Cambios tecnológicos en el contexto publicitario: Dinámicas y tendencias en investigación" (2015) Icono 14.

Lourdes Román Portas es doctora en Comunicación por la Universidad de Vigo. Hizo la tesis sobre "La retórica del texto argumentativo en la columna de opinión "Escenas Políticas" de Jaime Campmay (1983)" por la que obtuvo la calificación de Sobresaliente cum laude. Es licenciada en Filología Hispánica por la Universidad de Santiago de Compostela y licenciada en Filología Galego-Portuguesa por la misma Universidad. En la actualidad es profesora de lengua y literatura española en la Comunidad foral de Navarra. Ha publicado entre otros artículos "Una aproximación al análisis comparativo del léxico metalingüístico gallego-español", publicado por Editorial Edita. 